\title{
Apontamentos sobre ensino de História do Paraná
}

Lucinéia Cunba Steca ${ }^{I}$

\section{RESUMO}

Este artigo propõe uma reflexão sobre o ensino de História Regional, no que tange à forma e a conteúdo de História do Paraná, ministrado por professores, no Ensino Fundamental II segmento e no Ensino Médio, como (PEC) Projeto de Enriquecimento Curricular.

Palavras-chave: região, identidade, memória, regionalismo, ensino de História.

Na busca por outras formas de abordagem no ensino de História, pode constituir-se num repensar, e evidenciar-se como uma estratégia, o ensino de História através do conhecimento da história local. A globalização e a homogeneização, poderiam conferir à História Regional um papel importante na conscientização quanto à valorização do lugar de origem, para a integração social do indivíduo. Além disso, a possibilidade da pesquisa sobre a história local, por meio do ensino da História Regional, poderia ser capaz além de dirimir a distância entre a história local e a História do Brasil e Geral, revelar aos educandos seu papel enquanto agentes históricos, aduzindo-os como divulgadores de sua cultura.

O estudo desse recorte temático é polêmico, e a pesquisa realizada junto aos professores que ministram aulas de História do Paraná no ensino Fundamental $2^{\circ}$ segmento Ensino Médio, na modalidade de Projeto de Enriquecimento Curricular (PEC), ajuda-nos a visualizar se o modo como é ministrada a História do Paraná, relacionada à uma perspectiva bistórica conservadora, que não raro, pode restringir a região a uma construção que legitima uma bistória elitista. Dessa forma, procuramos compreender e refletir sobre o conceito histórico de região, regionalismo, identidade e memória regional.

\footnotetext{
1 Professora de História atualmente atuando no Centro de Educação de Jovens e Adultos (CEBJA), em Londrina-PR.
} 
0 interesse pela pesquisa sobre o ensino de História Regional, no caso específico da História do Paraná, remete-se também à ausência de uma clara definição teórico-metodológica para sua abordagem. Assim, buscamos repensar sobre a importância do ensino de História Regional, da ação consciente do professor-historiador em defesa do patrimônio histórico local e regional, devido a sua relevância para a compreensão geral da História.

Sobre o conceito de Região

A História Regional, até as últimas duas décadas do século XX, parece ter sido alvo de descrédito e objeto de várias discussões sobre sua produção, pois se dizia que o produto de semelhante abordagem seria pautado na "história relato" e/ou positivista. A partir dos anos 80 houve uma mudança de pensamento e passou-se a valorizar as investigações e produções de cunho regional, surgindo um grande questionamento no campo da historiografia, ocorrido talvez em função da própria necessidade de adaptar-se às transformações políticas porque passava o mundo, com o que ocorria no Leste Europeu. De qualquer modo, algo parece ter levado os historiadores a repensarem o seu procedimento teórico, e a reconhecê-lo como um modelo que deveria então ser abandonado.

Diversas correntes históricas apropriaram-se do conceito de região, e modificaram-no segundo seus pressupostos teórico-metodológicos, originando várias concepções. Entre as várias correntes, uma compreendeu esse conceito como sendo ideológico, dentro de uma concepção marxista, onde ele seria construído e imposto por uma classe dominante dentro de uma determinada espacialidade, numa temporalidade também delimitada. E outra concepção abordou região como algo construído historicamente e, portanto produzido e assimilado por ambas as classes, no próprio enfrentamento ao qual se impõe, onde não haveria uma homogeneidade completa por parte de nenhuma das classes. Pensamos que este último seja o que melhor corresponde a nossa concepção.

Silveira aludindo sobre o significado de região afirma que: "Não se atenta para o conceito de região e espaço enquanto construção, processo histórico concreto, portanto, atravessado pela temporalidade e nesta interferente." (SILVEIRA, 1990, p. 17). Esta consideração da autora, chama a 
atenção para um equívoco muito comum nessa análise, que seria a idéia de que a classe dominante, imporia sua ideologia ao dominado, que a receberia e assimilaria. Ao ressaltar que região é um espaço em construção, e que essa construção é histórica e, portanto um produto de seu tempo, a autora demonstra que não há semelhante intencionalidade ou premeditação de uma classe sobre a outra. Desse modo, o que podemos deduzir seria que ambos atores sociais, dominados e dominantes, seriam agentes nesse espaço (tanto simbólico como material) denominado região, e esse mesmo espaço poderia caracterizarse pela sua estrutura, conformação, e principalmente, historicidade.

Claro que poderíamos considerar região como também espaço físico, porém apresentando determinadas características que fariam desse espaço uma homogeneidade, não só no que tange aos aspectos físicos em si (clima, vegetação, solo, etc.), mas muito mais aos aspectos sociais, econômicos, e políticos. Essa configuração regional, que resultaria do próprio desenvolvimento de suas forças intrínsecas, em nada respeitaria determinações espaciais de fronteiras impostas, mas seguiria uma determinação consensual entre os componentes que the são formadores, interagindo umas com as outras.

Entre os críticos também estão aqueles que utilizam o sistema capitalista e o desenvolvimento tecnológico, possibilitado pela globalização, como um fator homogeneizador das sociedades humanas, que, segundo eles, descaracterizaria as regiões tornando o termo um discurso vazio de significação. De acordo com Oliveira ${ }^{2}$ as sociedades capitalistas apresentariam 0 desenvolvimento do capital de forma desigual, porém combinada, de modo que as relações capitalistas encarregar-se-iam de transformar regiões centrais e periféricas, que até então pudessem ter sido heterogêneas, e, portanto singulares em regiões homogêneas, uma vez que trariam em seu âmago os mesmos problemas característicos de uma sociedade capitalista, ou seja, a luta de classes e a defesa dos interesses de suas elites. Mas Silveira e Martins ${ }^{3}$ rebatem a argumentação de Oliveira, e leva-nos a concluir que o capitalismo pode homogeneizar um determinado espaço, mas não sem o enfrentamento e a resistência das singularidades que lhe conferem identidade.

\footnotetext{
2 Apud in: SILVEIRA, Rosa Maria Godoy. Região e História: Questão de Método. In República em Migalbas: História Regional e Local. São Paulo: Editora Marco Zero, 1990. (p.38-1$).

3 MARTINS, Paulo Henrique N.,. O Nordeste e a Questão Regional: os equívocos do debate. in Repuíblica em Migalhas: História Regional e Local. São Paulo: Editora Marco Zero, 1990. (p.65-1̊)
} 
Tais críticas permitem questionar a possibilidade de uma história isenta de intencionalidade política. E quanto à sustentação teórico-histórica do termo região, o que dizer sobre o uso da história das regiões econômicas centrais como eixo para a construção de uma história nacional? ${ }^{4}$

Nem todos os historiadores pensam que ao mergulhar no estudo da região, e ano lidar com a especificidade, perder-se-ia, necessariamente, a dimensão da totalidade. Há quem defenda que seria essa totalidade que dimensionaria 0 estudo que estaria sendo realizado, não com a intenção de fragmentar o todo e chegar as partes e vice-versa, mas no sentido de compreender o processo histórico num dado momento espacial e temporal recortado para estudo, onde a totalidade seria o seu contexto histórico.

Pesavento compara os conceitos clássicos de região em Lênin e em Gramsci, e aponta-nos uma diferença, pois "[...] na abordagem gramsciana, se possibilita a análise da especificidade espacial a partir da dinâmica das classes num contexto historicamente delimitado" (PESAVENTO, 1990, p.68$5^{\circ} \S$ ) Desse modo, somos levados a entender região como sendo o espaço de enfrentamento de classes, o local de reprodução do capital. Ela observa que no conceito de região existiria a especificidade econômico-social resultante da própria forma das relações sociais de produção, bem como também haveria um caráter político-ideológico, que resultaria das relações de poder usadas na construção do que seria uma identidade local.

Priorí apresenta o conceito de região como "espaço social construído historicamente". Ele ressalta que esta construção histórica estaria ligada à cultura do historiador, à idéia de espaço, tempo e história que o historiador poderia ter, bem como da escolha de sua problemática para o estudo de uma determinada região. Assim, podemos afirmar que o conceito de região seria uma construção simbólica relacionada ao concreto, concebida socialmente e recriada pelos historiadores quando tomam o objeto, região, como alvo de investigação histórica. Poderíamos pressupor ainda que esta investigação somente se realiza mediante um recorte espacial e temporal, que deve levar em consideração tanto a formação sócio-cultural ali presente, quanto o

4 Como exemplo de explicação da história geral a partir de aspectos regionais-locais, ver SEVCENKO, Nicolau. Literatura como missio. Sp. Brasiliense, 1999.

5 PIORI, Ângelo, História Regional e Local: Métodos e fontes. In Pós-História. Assis: Editora UNESP, v. $4,1994$. 
desenvolvimento das relações econômico-políticas, pois através destes indícios é que se configuraria a chamada identidade regional.

\section{História Regional e Regionalismo}

0 aspecto da História Local-Regional mais criticado parece referir-se ao risco constante de valorizar somente as singularidades, reproduzindo uma espécie de história relato. Por isso, torna-se interessante a esquematização que podemos fazer a partir da análise de Queiroz e Silva $a^{6}$, segundo a qual, haveria diferenciação entre História Local e História Regional, existindo a História Local, que restringir-se-ia ao relato da história do bairro e da cidade; a História Regional, criada pelo senso comum e definida por costumes ou origem, onde as fronteiras seriam indefinidas; a História Regional oficial, que seria definida no papel pelos aspectos físicos (clima, solo e vegetaçãa, etc) e a história oficial representada pelo discurso sobre a época de colonizaçã̃o. Haveria também a história da unidade da Federação criada pelo senso comum, contada por pioneiros e fontes diversas não oficiais e a história oficial da unidade da Federação, que seria construída pelas classes dominantes e pela elite política do Estado.

Desta esquematização, pode parecer que o ideal seria ressaltar a História Regional da uniclade da Federação sob o ponto de vista comum: costumes/ origem, somando-se ao relato de pioneiros" e as fontes não oficiais, buscando inseri-las no contexto de História do Brasil, América e Geral, além do que, tentar fazer a ponte entre passado e presente, mantendo como um compromisso o ensino de uma História Regional crítica.

Avaliando o papel do regionalismo para a interpretação histórica, Cardoso Silva' ressalta a diferença do Regionalismo como método de investigação e como concepção interpretativa. Na sua visão, a importância da História Regional residiria no seu objetivo, ou seja, no conhecimento das diferenças regionais, e não na promoção de uma política regionalista ou de suas elites regionais,

\footnotetext{
6 SILVA, Jorge Antonio de Queiroz e. Globalização e História Local. In Revista História E Ensino. Revista do Laborátório de Ensino de História. Londrina: Editora UEL, 2001

* Entendemos como pioneiros todas as pessoas que participaram de alguma forma do processo histórico.

7 SILVA, Vera Alice Cardoso. Regionalismo: 0 Enfoque Metodológico e a Concepção Histórica. In República em Migalhas: História Regional e Local. São Paulo: Editora Marco Zero, 1990. (p.45-4̊).
} 
como imposição do poder local. Para a autora, a História Regional deveria ter o Regionalismo como objeto, e sua investigação dar-se-ia através e por meio da história comparada.

Cardoso Silva parece levar-nos a compreender que, de um lado, se enfocarmos o Regionalismo como concepção interpretativa, culminaremos num reducionismo, ou seja, a pesquisa voltar-se-ia para o discurso da história da unidade da Federação, ou da região ou de localidades, mas sempre o oficial e, portanto eivado de intenções políticas, desenvolvidas ou aspiradas por suas elites. Desse modo, o que se produzisse nesta linha, poderia resultar em promoção da classe dominante. De outro lado, se adotarmos o Regionalismo como método de investigação, então talvez, se pudesse possibilitar a análise sobre como as decisões tomadas em nível macro, no aspecto político-social e econômico, foram sentidas regional e localmente, e como foram assimiladas ou refutadas, ou transformadas pelas sociedades, que por elas foram atingidas. Mas o uso de uma concepção interpretativa do Regionalismo é bastante real. Estão aí os compêndios didáticos variados que o comprovam.

\section{A identidade regional}

Ao nos reportarmos a uma História Regional parecemos estar tentando fragmentar o todo. Mas na realidade não conseguimos, dependendo do recorte temático, necessariamente, unir sociedades regionais em torno de um eixo histórico único, porque estará provavelmente sujeito às influências que resultam dos embates entre as classes sociais envolvidas, tanto no âmbito local, quanto nacional, e mesmo global ${ }^{8}$.

Para chegar a ponto de formar uma história comum, hegemônica, seria necessário que se adotasse um discurso onde cessassem os conflitos de interesses entre as elites regionais, ou que esses interesses fossem convergidos, estrategicamente, para um objetivo comum. ${ }^{9}$ Pensar numa história unificada, no sentido de entender que as regiões teriam a mesma origem, dinâmica, formação, funcionamento, seria

8 Idem, p.49-1'\$ e $2^{\circ} \$$.

9 PESAVENTO, Sandra Jatalyy. História Regional e Transformação Social(Comentário do texto "Região e História"). In Repriblica em Migalhas: História Regional e Local. São Paulo: Editora Marco Zero, 1990. $\left(p .77-5^{\circ} \xi\right)$ 
pensar numa história que não consideraria as diversidades regionais enquanto dimensionadoras do discurso histórico, tornando-o portanto dominante enquanto discurso, sobre todas as demais histórias locais. Sendo dominante, seria homogêneo e, provavelmente, não explicitaria a luta de classes. Mas, os excluídos desse discurso, continuariam a interagir pelo menos de duas formas: assimilando o discurso histórico dominante como sendo sua história também; ou rejeitando-o, transgredindo-o, recontextualizando-o, no todo ou em parte, por não se sentirem integrantes dele.

No primeiro caso é possivel afirmar que houve uma imposição do discurso histórico dominante, e que se obteve uma história oficial unificada. Mas, no segundo caso, talvez como resultado da própria diversidade cultural e da própria luta de classes, haveria uma grande resistência por parte dos dominados, e o que se poderia verificar seria um discurso oficial, sutilmente adaptado às singularidades específicas. Em ambos os casos se pode inquirir sobre a questão da identidade. Se ousássemos questionar sobre o que é ser paranaense, detectaríamos uma identidade única, ou ela seria múltipla?

De acordo com Tadeu da Silva identidade está necessariamente ligada ao poder, porque produzida nas relações sociais, e construída numa realidade dinâmica e contraditória, enfim, produzida historicamente. ${ }^{10}$

Para Contijo" ${ }^{11}$ identidade pode ser entendida como construção histórica, e por isso precisaria "[...] ser continuamente reinventada e reinvestida de significados e sentidos, e a partir de situações históricas específicas." (2003, p. 55-1ㅇ). Podemos compreender que esse domínio de significações dar-se-ia dentro de um grupo social. Dessa forma, a identidade seria algo que criaria afinidades, que aproximaria e uniria um grupo social no passado e no presente, e acabaria representando aquilo que faria a distinção entre esse grupo determinado e os outros. Essa distinção, essa singularidade, extrapolada para a questão do espaço é que daria origem à região.

Identidade seria portanto fator de identificação pessoal, a partir de algo que fosse comum entre as pessoas do grupo no qual se estaria inserido. Essa identidade seria construída pela sociedade, sobre signos importantes somente

\footnotetext{
${ }^{10}$ SILVA, T.T. (org.) Identidude e Diferença: A perspectiva dos Estudos Culturais. Petrópolis: Editora Vozes, 2000.pp. 76. (p. 76).

11 CONTIJO, Rebeca. Identidade Nacional e Ensino de História: A diversidade como patrimônio sócio cultural. In ABREU, Martha; SOIHET, Rachel (orgs.). Ensino de História:Conceitos, temáticas e metodologia. Rio de Janeiro: Editora Casa da Palavra, 2003.
} 
para as pessoas daquele grupo social. Fora do grupo, esses signos poderiam ter outros significados ou mesmo, significado algum. Assim, parece unânime entre os autores referenciados, considerar que não se deve reduzir o conceito de identidade a um artefato, uma vez que não seria uma imposição articulada propositalmente pela classe dominante.

Se pensarmos o Paraná como unidade da Federação, e analisarmos historicamente seu desenvolvimento sócio-político-econômico, poderemos perceber que ele ocorreu de forma desigual e em tempo desigual. Poderíamos pensar que esse processo originou vários grupos sociais diferentes, com interesses diferentes e nem sempre convergentes entre si. Desse modo, seria possível argumentar que esse espaço, denominado Paraná, possui várias identidades, com signos diferentes e que só têm em comum uma mesma relação de significância interna, entre cada grupo. Consideramos que em termos de História do Paraná não parece haver a elaboração de um discurso unificado, mas vários discursos re-significados, que poderiam ser entendidos enquanto comuns.

Se partirmos do princípio de que a História Regional baseia-se nas singularidades dos grupos que formam as sub-regiões, e que esses grupos distinguem-se uns dos outros pelos signos que lhes conferem identidade, então poderemos afirmar que o estado Paraná não possui uma identidade, e que essa identidade está para ser construída. Mas se ela não existe, o que impede a fragmentação do Estado? Seria a crença no signo do trabalho? A crença coletiva de que o Paraná é um Estado que "se fez" pelo trabalho, de imigrantes, "pioneiros", indígenas e negros? Mesmo não sendo um signo exclusivo do Paraná, quando dizemos que o "trabalho" pode ser considerado uma marca identitária paranaense, outras características são associadas a essa marca: 0 caráter forte, empreendedor, pioneiro, a propensão ao sacrifício, à abnegação, qualidades consideradas próprias ao povo de determinada região.

A resposta poderia talvez, estar na forma como foi construído o discurso, não sobre esse "trabalho", mas sobre o modo como ele foi realizado. Pensamos que adotando um discurso sobre a edificação do estado através do trabalho, poderíamos obter uma certa distinção entre nós e os outros. Os outros, os não paranaenses, não teriam as nossas qualidades. Se esquecermos por um momento que se trata de uma idéia extremamente etnocêntrica, não se pode relevar o fato de que isto poderia transformar-se num fator de identidade coletiva. 
É preciso pensar também que a re-construção da história pelo historiador tem como efeito a elaboração e a concepção de uma identidade. Sobre isso Arias Neto ${ }^{12}$, afirma que "Reintegrar o passado, perceber a identidade presente e projetar um futuro mais justo e mais humano constitui a dimensão política do trabalho do historiador [...]".(1995, p. 81-3ㅇ). Talvez essa identidade construída pudesse ser regional, múltiplas, e mesmo assim, tão bem articuladas entre si, pelo discurso por exemplo do trabalho, que não nos aperceberíamos de suas divergências sutis. Essa identidade, segundo Bittencourt ${ }^{13}$ (2000, p. $144-2^{\circ} \S$ ), sob o efeito da globalização, parece querer transformar a todos em verdadeiros "cidadãos do mundo". A identidade nacional, aparentemente, estaria sofrendo uma descaracterização causada pelo que Azevedo ${ }^{14}$ chama de "organismos supranacionais". Segundo a autora, estes organismos invadem o espaço social e questionam ou desmistificam a relação simbólica outrora construída. Questiona a autora "Em que medida a insistência atual na identidade nacional poderia representar uma resistência conservadora ao fenômeno da hibridização?" (AZEVEDO, 2003, p. 46-3§ e p. 47).

Analisando a questão, parece-nos que o que ocorreria seria um processo de justaposição cultural e não de hibridização, no sentido de que a sociedade envolvida pode adotar certos símbolos integralmente, transformar outros, total ou parcialmente, ou rejeitar outros totalmente. Dessa forma, sendo uma justaposição, a "insistência atual na identidade nacional", citada pela autora, seria necessária para manter ou buscar manter um certo equilibrio cultural. Porém, é possível cogitar se esta não poderia ser uma fonte da crise de identidade que se vive hoje, diante do esquecimento do passado, pois na ânsia de tornarmonos iguais, perdemos o referencial sobre quem somos ${ }^{15}$.

A experiência de tentar montar uma identidade, por meio da articulação de uma elite intelectual, já foi realizada nos idos anos de 1950, através do

\footnotetext{
12 ARIAS NETO, José Miguel. Pioneirismo: Discurso Político e Identidade Regional. In História \& Ensino. Revista do Laboratório Ensino de História. Londrina: Editora UEL, n 01, 1995.

13 BITTENCOURT, Circe Maria Fernandes. Propostas Curriculares de História:Continuidades e Transformações. In BARRETO, Elba (org.) Os Currículos do Ensino Fundamental para as escolas brusileiras. $2^{\mathrm{a}}$ ed., Campinas: Editora Autores Associados, 2000.

${ }^{14}$ AZEVEDO, Cecília. Identidades Compartilhadas: A identidade nacional em questão. In ABREU, Marta; SOIHET, Rachel (orgs.). Ensino de História: Conceitos, Temáticas e Metodologia Rio de Janeiro: Editora Casa da Palavra, 2003.

15 PESAVENTO, 1990, p.70-5०\$ e p. 71.
} 
Paranismo. Esse movimento, produzido naquele momento histórico como resposta a uma necessidade de auto-afirmação de um Estado frente à Federação, ${ }^{16}$ é um claro exemplo de como a identidade está relacionada com as relações de poder, pois quando se diz quem somos "nós" e quem são os "outros", também se afirma quem pode estar incluído e quem deve estar excluído, independentemente do poder político.

No momento histórico atual, pode parecer que este questionamento não tem mais fundamento, entretanto, a busca por uma identidade continua. Então, porque ainda não desenvolvemos uma identidade, e estamos mergulhados numa verdadeira crise? Ante as várias considerações refletidas, podemos perceber que uma identidade única para o Paraná não existe. 0 que existem são múltiplas identidades regionais. Porém, é a partir dessas identidades múltiplas que se busca criar uma identidade única e específica, tentando dar resposta à questão do que é ser paranaense.

Ao que parece, para a elite, esta criação pode ser erigida de forma tradicional, através do uso de símbolos, que pouco ou nenhum significado tenha para a população, e que não permitem o questionamento do real, garantindo a continuidade de um certo domínio social e político. Porém, parece-nos que o mais correto, como resultado do embate entre as classes no interior da sociedade, seja a possibilidade da construção de tal identidade, fazendo-a de tal modo coletiva que possibilite um resgate da nossa história, através da problematização das fontes, do questionamento crítico e da análise da realidade, tornando-a um instrumento capaz de levar à compreensão das diferenças e das contradições sociais. Dessa forma, a construção de uma identidade coletiva teria sentido, pois poderia levar um povo a aprender a se unir e a lutar pela construção de uma sociedade melhor.

Memória regional

Memória é o passado? De acordo com Sobral, memória seria uma noção de passado diretamente ligada à identidade, pois para ele, "A identidade é uma

${ }^{16}$ BURMESTER, Ana Maria, PAZ, Francisco Moraes, MAGALHÃES, Marionilde Dias B. 0 Paranismo em questão. In: República em Migalbas: História Regional e Local. São Paulo: Editora Marco Zero, 1990. (p. $159-5^{\circ}$ e $\left.6^{\circ} \$\right)$ 
elaboração necessária para manter a coerência e a continuidade do ser individual e pressupõe memória. [...] Sem memória e um sentimento de identidade, não há segurança ontológica." (1998, p. 40-2§ e p.41) Desse modo, parece-nos que o passado seria construído na busca de uma origem, só que seria um passado que não diria respeito, por exemplo, ao Estado como um todo. Esse passado dependeria da significação e ressignificação feitas pela sociedade, e esse processo seria completamente diferente em cada grupo social, pois seria pertinente apenas àqueles que o construíram e reconstruíram.

É óbvio que conceber a memória só seja possível através de lembranças, e as lembranças, sendo únicas, pessoais e intransferíveis, dependem de um respaldo social, Dessa forma, memória pode ser traduzida como uma imagem que se faz do passado e não a imagem do passado propriamente dita, porque seria continuamente reconstruída de acordo com os interesses pessoais de cada indivíduo. ${ }^{17}$ De acordo com Cassirer ${ }^{18}$, é possível observar que são lembrados os fatos que trazem em si a história dos vencedores, da classe dominante e, por isso mesmo, estes são os recordados coletivamente. Mas existe uma lembrança pessoal, aquela dos dominados, que permanece viva e que faz lembrar o mesmo fato, mas de forma diferente.

Entendemos que a idéia de possibilitar um resgate da memória regional teria como objetivo a tentativa de desenvolver nas pessoas um sentimento de origem, e de poder remeter-se a uma identidade e memórias coletivas, que foram construídas por seus antepassados. O que seria importante considerar enquanto memória histórica, estaria ligado às relações que o indivíduo tivesse com a sociedade na qual está inserido ${ }^{19}$ A História Regional então poderia manter viva a memória histórico-cultural ${ }^{20}$.

Arias Neto compreende a memória como um direito a ser exercido no interior da sociedade, afirmando que "Para todos deve ser estendido o direito à memória, e este direito - como todos os outros - só pode existir enquanto práxis social". (1995, p.81-4요). Desse modo, podemos perceber que além de

\footnotetext{
${ }^{17}$ SOBRAL, José Manuel, Memória Social e Identidade. Experiências Individuais. Experiências Coletivas. In CARDIM. Pedro (org) A História: Entre Memória e Invenção. Portugal: Editora Publicações EuropaAmérica, 1998. (, p.39-1$)

Is CASSIRER, Ernst. Ensaio sobre o bomem. São Paulo: Editora Martins Fontes, 2000.

19 BOSI, Ecléa. Memóric e Sociedade. São Paulo: Editora Companhia das Letras, 1999. (p. 54).

20 Idem, p. 68 e 75
} 
um direito, a memória constituir-se-ia num fator humanizador ${ }^{21}$, um privilégio humano que se expressa pelo poder dar-se a conhecer o que passou através de imagens construídas no presente e, quem sabe, reconstruídas de modo diferente, no futuro. Talvez a tarefa mais grata da história regional seja justamente a busca por estas memórias.

Sobre o objetivo do ensino de História Regional no Ensino Fundamental $2^{\circ}$ segmento e Médio.

A História Regional poderia vir a ser um caminho para se conscientizar o indivíduo de que ele pertence a algum lugar, e poderia dar às pessoas um ponto de referência, que seria muito importante, na medida em que, nos dias atuais, a globalização cultural tende a fazê-las crer que estão "livres" desses referenciais. Esta "liberdade" logo expressa-se por uma crise de identidade, pois mesmo sem sair do seu lugar de origem, as pessoas recebem informações sobre o mundo, passadas pela mídia, e que nem sempre correspondem à realidade. Assim, de certa forma, se colocando a contraponto com o discurso globalizado eficiente que os qualificam enquanto "cidadãos do mundo", poderia surgir o ensino de História Regional, resgatando a memória, o valor do patrimônio histórico e a importância de se ter uma identidade que é respaldada coletivamente, dentro de uma sociedade real, e não virtual, apresentada pela mídia.

Pesavento 22 afirma que foi a partir da década de 1970, que começaram a surgir teses calcadas em estudos regionais, feitos a partir da análise de fontes locais. Essa regionalização curricular, segundo a autora, teria originado uma espécie de produção biográfica das unidades da federação e de algumas de suas cidades, numa história relato, baseada no regionalismo. Portanto, a História Regional, que se apresentava naquelas produções, seria uma simples curiosidade que se encerravam sobre si mesmas, na medida que meramente visavam informar fatos pitorescos e nomes de ilustres "pioneiros" e fundadores. Nessa visão, podemos questionar onde teria ficado o caráter transformador da sociedade, que é atribuído ao ensino de História já na épocá.

\footnotetext{
${ }^{21}$ Sobre o assunto ver CAINELLI, Marlene. História do Brasil, Histórias de Brasileiros:História, passado e identidade na memória popular. Curitiba: Para finalizar gostaríamos de agradecer a coordenação do curso de Especialização e ao Departamento História da UEL que viabilizou os recursos para a publicação deste número de História \& Ensino.7UFPR, 2003.

22 PESAVENTO, 1990, p. $67-4^{\circ} \$$.
} 
Sobre esse papel transformador do ensino de História, Davies afirma que o ensino de História deve ter como objetivo uma ação transformadora da sociedade, mas ele ressalta que não se pode atribuir esta tarefa exclusivamente à prática docente do professor. Para esse autor, é fundamental integrar o particular com o geral em História, e o estudo do passado deve abranger vários aspectos, como o econômico-político, sócio-cultural, em vários tempos e espacialidades. Parece necessário também não trabalhar a História dentro de um esquema positivista. Dessa forma, se relacionarmos o particular com o geral, talvez possamos romper com este tipo de visão reducionista. 0 grande objetivo de estabelecer esta ligação, segundo Davies, seria um desafio da educação escolar. ${ }^{23}$

Segundo Penteado ${ }^{24}$ seria possível tornar a aprendizagem baseada nos conteúdos dispostos em círculos concêntricos (da "parte" para o "todo") mais dinâmica, na medida em que tais conteúdos poderiam ser apresentados sob várias temáticas e em várias temporalidades, permitindo a análise e a reconstrução daquela realidade estudada, "[...] num movimento constante que vai tanto das partes para o todo como do todo para as partes." (PENTEADO, 1994, p.33).

0 conhecimento da história local então poderia ter como objetivo instrumentalizar o indivíduo para que ele pudesse entender, criticamente, o que é efêmero, modismo, o que é "imposto de fora", o que seria manipulação e assim ter condições de aceitar, transgredir, resistir ou assimilar em parte a chamada "cultura global". ${ }^{25}$

o problema seria como conscientizar o indivíduo quanto a valorizar seu patrimônio histórico e sua memória em virtude dessa "invasão", se aos seus olhos "o de fora" parece mais merecedor de sua consideração e apreciação? Talvez, o "despertar" de uma consciência histórica já seja uma ação transformadora, que apesar de menosprezada pelo Estado e subestimada pelo

23 DAVIES, Nicholas. Elementos para a Construção do Currículo de História. História \& Ensino. Revista do Láboratório de Ensino de História. Londrina: Editora UEL, n. 2, 1996. (p. 34, 25330-1$).

24 PENTEADO, Heloísa Dupas. Metodologia do ensino de bistória e geografia. São Paulo: Editora Cortez, 1994.

${ }^{25}$ SANTOS, 1997, p.196 apud SILVA, Jorge Antonio de Queiroz e. Globalização e História Local. In Hisiória \& Ensino. Revista do Laboratório de Ensino de História. Londrina: Editora UEL, 2001. (p. 88).

26 Referimo-nos aquui ao cuidado que algumas administrações públicas municipais paranaenses têm com a organização de festas do tipo uma "Semana Country", e ao mesmo tempo, apesar de terem ciência, não tomam nenhuma providência com relação às condições em que se encontra o "acervo histórico" da cidade. 
professor em sua prática, poderia levar alunos e professores à distinção sobre 0 que seria hábito e o que seria tradição. Assim, a participação histórica do aluno seria importante para que fosse diminuída a distância que pode ser percebida entre a história pessoal e a geral, deixando transparecer que a História é sempre a história dos outros e não a sua. Mas ao se perceber inserido nela, poderia também se identificar enquanto o seu construtor.

Se observarmos, poderemos perceber que no Paraná, no entender burocrático, oficial, espera-se que o ensino de História Regional se realize mediante apenas da criação e do decreto de uma lei. É possível perceber que não se previu a operacionalidade da execução desse projeto, levando em conta as dificuldades estruturais e humanas.

Uma das sugestões dos autores Manique e Proença ${ }^{27}$, para se trabalhar com o ensino local, seria através do uso de arquivos locais. De certa forma, esse trabalho de campo, muitas vezes dificultado por vários motivos, poderia ser um caminho didático que levaria o aluno a conhecer sua história de forma mais concreta, e aprender a diferenciar patrimônio público do patrimônio privado, além de identificar o que seria patrimônio histórico, aprendendo a valorizar sua conservação, para a preservação da sua memória e identidade. E consideramos importante não somente o testemunho dos monumentos e arquivos, mas também a história oral, viva na fala de todos aqueles que fizeram parte da história em outros tempos. Portanto, para o ensino de História Regional, seria preciso buscar uma metodologia e didáticas que possibilitassem a corelação entre as diversas visões de história que se apresentam.

A História ensinada: Regional ou Regionalista?

A preocupação das elites para com uma integração ideológica de todos os habitantes do Estado poderia se dar através do ensino, não de uma História Regional, mas Regionalista. ${ }^{28}$

Para Gonçalves, uma motivação apontada, seria a necessidade de auto-

${ }^{27}$ Manique, Antonio Pedro. PROENÇA; Maria Cândida. Didática da História: Patrimônio e História Local. (Comentários e considerações sobre a reforma educacional do ensino em Portugal final dos at ${ }_{i}{ }^{\prime}$ s 1990). Lisboa: Texto Editora, 1994. (p. 23-2 $2^{\circ}$ \$).

${ }^{28}$ GONÇALVES, José Henrique Rollo. Alguns Problemas do Ensino Escolar de História Regional. História \& Ensino, Revista do Laboratório de Ensino de História. Londrina: Editora UEL, n. 04, 1998. (p.64). 
afirmação da elite paranaense frente as demais elites nacionais e, por isso, o grande esforço de tentar construir e manter uma identidade paranaense, onde permaneçam vivas na memória a importância de sua ação para a emancipação e formação do Estado.

Dessa ação prescinde forjar uma identidade para que as pessoas se sintam enquanto "paranaenses" no sentido político-ideológico, quase como um "paranismo". É bem provável que não seja a necessidade de criar uma identidade real, aquela que permitiria uma sensação de pertencimento a algum lugar, pois essa seria uma identidade regional e portanto, fragmentada. Podemos conferir desse ponto de partida, a necessidade criada pelo Estado de fazer conhecer a História oficial de si mesmo, com seus heróis, seus fatos importantes para a classe dominante, mas que nem sempre significam muita coisa para as demais.

Compete-nos lembrar que a História do Paraná, regionalista/paranista continua nos discursos oficiais. Um decreto do governo anterior, lei $n^{0} 13381$, impõe um ensino em que se deve criar a identidade paranaense através de determinados conteúdos históricos escolares ministrados no Ensino Fundamental e Médio. 0 documento considera que a Bandeira, o Escudo e 0 Hino do Paraná devem ser estudados. Evidentemente, dependerá de como tais itens serão trabalhados em sala de aula para configurar um ensino tradicional ou renovado, mas o documento demonstra claramente seu conteúdo tradicionalista ao decretar que, semanalmente, o Hino do Paraná deverá ser cantado, a Bandeira do Paraná hasteada e as datas comemorativas festejadas.

0 exercício de reflexão entre passado e presente, de criticidade em relação à História, pode ficar à margem, correndo o risco de passar a depender exclusivamente do professor para estar sendo realizado. 0 enfoque que se confere a esse ensino, portanto, estaria dependente da formação, da atualização e da consciência do professor, pois do contrário, as aspirações elitistas seriam atendidas, através de uma bela história relato, calcada em uma abordagem regionalista, baseada em biografias de cidades e não em uma História Regional crítica.

O Ensino de História Regional: A realidade dos professores e das salas-de-aula

Discorrer sobre a realidade prática do ensino de História Regional, pode muito bem ser traduzido pelo inventário dos inúmeros óbices encontrados para a realização do trabalho docente neste Estado e neste país. 
0 resultado da pesquisa realizada junto a 11 professores da rede estadual de ensino que ministram aulas de História do Paraná, para o ensino Fundamental II Segmento e Médio, como Projeto de Enriquecimento Curricular (PEC) possibilitou-nos conhecer alguns aspectos da realidade do ensino escolar de História Regional. ${ }^{29}$

0 que tudo indica, embora haja o discurso de renovação do ensino de História, os professores podem dizer que trabalham por eixos temáticos, mas isso não parece acontecer na prática. Além disso, fazer a relação passado/ presente consta nos currículos de História da atualidade em comprometimento com uma tendência historiográfica denominada "renovada", no entanto, o resultado da pesquisa demonstrou que o que seria "novo" é realizado na prática sob preceitos do "velho" ensino de história, etapista/evolucionista.

Com base no resultado da pesquisa foi possível perceber que além da separação entre pesquisa e ensino, haveria a falta de livros didáticos adequados aos graus de ensino. Essa ausência por si já denota a falta de interesse das próprias editoras para com a publicação de livros de cunho regional, destinados ao ensino Fundamental II segmento e Médio, e o não menos grave, diante da questão, que seria o uso de material inadequado não como referencial, mas como suporte para esse ensino.

Talvez o maior problema seja que a maioria dos materiais usados para o ensino de História do Paraná, na fase II do Fundamental e Médio, sejam materiais do Ennsino Fundamental do I segmento. Logo, podemos deduzir que não há apoio ao professor no sentido de fazer com que ele tenha acesso a material didático adequado para ministrar aulas sobre a História do Paraná.

Segundo Alarcon Agra do $0^{30}$ seria simplista a imagem do professor como um não-leitor, como não interessado em retomar a historiografia para planejar suas aulas, pois devemos considerar qual leitura que é possível no

\footnotetext{
29 História do Paraná é uma disciplina não ensinada em muitas escolas. Atualmente, são 126 escolas estaduais em Londrina, sendo que a parte diversificada do currículo de ensino não é trabalhada por todas as escolas. A srande maioria năo t: aibalha com PEC de História, mas de outras disciplinas. 08 escolas oferecem PEC de História, sendo que não determinam que o conteúdo trabalhado seja sobre História Regional. 03 escolas oferecem História do Paraná e 03 escolas oferecem PEC de História do Paraná. Desse modo, considerando o PEC de História do Paraná, e o estamos considerando, a amostragem pode ser considerada razoável.

30 AGRA DO Ó, Alarcon. Ensaiando um diálogo: história "acadêmica" e história "ensinada". In Saeculum. João Pessoa: Editora Universitária UFPB, n 8/9. pp. 157-178, jan/dez 2002-2003.
} 
presente para esse sujeito. (2002/2003, p. 159). Porém, a falta de formação adequada do professor para ensinar História Regional, a falta do domínio dos conceitos, a falta de recursos financeiros para aquisição de boas e relevantes leituras e a ausência de cursos de atualização, fazem com que a tarefa do professor de História do Paraná seja muito árdua.

E acrescentamos em relação a essa impossibilidade do professor retomar a "teoria" a questão dos baixos salários, e do aumento da carga horária de trabalho. Eles estão sozinhos para pensarem quais metodologias e conteúdos trabalhar, e enfrentam a falta de infra-estrutura escolar, não sendo muito difícil inferir quanto à dificuldade do professor ministrar aulas de História do Paraná com criticidade. Desse modo, o currículo escolar pode propagar a "renovação" e a autonomia do professor, mas será o ensino tradicional, que o professor já conhece e guardou na memória que irá prevalecer.

A situação de Projeto de Enriquecimento Curricular (PEC) coloca a História do Paraná como "estudo de caso", e o professor que não discernir entre o que é História Regional e regionalista, poderá ter sérias dificuldades para levar o aluno a fazer a ligação entre local e geral. Para muitos professores a própria formação universitária não privilegiou essa visão de inserção.

Pensamos que a História, que os professores querem, é uma História crítica, que retome a questão do Estado e o seu verdadeiro papel no processo histórico do páís. Mass, nossa pesquisa revelou que o professor não está conseguindo ministrar aulas de História do Paraná sob pressupostos teóricos-metodológicos renovados. Entretanto, qualquer reflexão que se faça sobre a questão, não pode atribuir culpas ou distribuir responsabilidade individualizadas.

\section{Considerações Finais}

A História Regional e o conhecimento da história local dos educandos, poderiam constituir-se numa temática de ensino de História que ampliaria a compreensão sobre a importância da preservação da memória histórica para a construção de uma identidade, o que permitiria conduzir a uma maior integração social, explicitando a ação transformadora dos indivíduos enquanto atores históricos. A pesquisa sob esse método, relacionaria a história local com a História do Brasil e Geral, revelando aos educandos seu papel de agentes históricos. 
A idéia do "ser paranaense" seria uma elaboração identitária coletiva que resultaria do embate entre as classes no interior da sociedade, e para identificar esse processo seria necessário resgatar a história através da problematização das fontes, do questionamento crítico e da análise da realidade, tornando-a um instrumento que permitiria compreender as diferenças e as contradições sociais, levando à formação de uma sociedade melhor.

Para o ensino de História Regional seria preciso buscar metodologia e didáticas que possibilitassem a co-relação entre as diversas visões de história que se apresentam, o que implicaria numa certa autonomia curricular das escolas, quanto à definição e elaboração de seus projetos, na atualização profissional dos professores e no apoio didático-pedagógico. Muito embora os "resultados" da pesquisa demonstrem uma situação do ensino de História do Paraná, que está longe de ser a ideal, a responsabilidade não pode ser atribuída diretamente ao professor, que de acordo com a pesquisa, encontra-se perdido e, muitas vezes, sem nenhum norteador para a sua tarefa.

De acordo com a "fala do professor" constatada pela pesquisa, podemos ter uma noção sobre qual História do Paraná está "chegando" até nossos alunos, que provavelmente tende a ser tradicional/regionalista. Assim, consideramos a relevância de uma reflexão sobre o ensino de História Regional buscando uma maior e melhor compreensão quanto à importância da formação de uma cidadania consciente.

\section{Bibliografia}

AGRA DO Ó, Alarcon. Ensaiando um diálogo: história "acadêmica" e história "ensinada". In Revista Saeculum. João Pessoa: Editora Universitária UFPB, n 8/9, pp. 157-178, jan/ dez 2002-2003.

ARIAS NETO, José Miguel. Pioneirismo: Discurso Político e Identidade Regional. In Revista História \& Ensino. Revista do Laboratório Ensino de História. Londrina: Editora UEL, n 01, 1995.

AZEVEDO, Cecília. Identidades Compartilhadas: A identidade nacional em questão. In ABREU, Marta; SOIHET, Rachel (orgs.). Ensino de História: Conceitos, Temáticas e Metodologia. Rio de Janeiro: Editora Casa da Palavra, 2003. 
BITTENCOURT, Circe Maria Fernandes. Propostas Curriculares de História: Continuidades e Transformações. In BARRETO, Elba (org.) Os Currículos do Ensino Fundamental para as escolces brusileiras. $2^{a}$ ed... Campinas: Editora Autores Associados, 2000.

BOSI, Ecléa. Memória e Sociedade. São Paulo: Editora Companhia das Letras, 1999. (p. 54).

BURMESTER, Ana Maria, PAZ, Francisco Moraes, MAGALHÃES, Marionilde Dias B. 0 Paranismo em questão. İn: República em Migalhas: História Regional e Local. São Paulo: Editora Marco Zero, 1990. (p. 159-5 e 6$)

CAINELLI, Marlene. História do Brasil, Histórias de Brasileiros: História, passado e identidade na memória popular. Curitiba: UFPR, mimeo(Tese de Doutorado). 2003.

CASSIRER, Enst. Ensaio sobre o bomem. São Paulo: Editora Martins Fontes, 2000.

CON'TIJO, Rebeca. Identidade Nacional e Ensino de História: A diversidade como patrimônio sócio cultural. In ABREU, Martha; SOIHET, Rachel (orgs.). Ensino de História: Conceitos, temáticas e metodologia. Rio de Janeiro: Editora Casa da Palavra, 2003.

DAvIES, Nicholas. Elementos para a Construção do Currículo de História. In Revista Históric \& Ensino. Revista do Laboratório de Ensino de História. Londrina: Editora UEL, n. 2, 1996. (p. 34, $\left.25330-1^{\circ} \$\right)$.

GONÇALVES, José Henrique Rollo. Alguns Problemas do Ensino Escolar de História Regional. In História \& Ensino, Revista do Laboratório de Ensino de História. Londrina: Editora UEL, n. 04, 1998. (p.64).

MANIQUE, Antonio Pedro. PROENÇA; Maria Cândida. Didática da História: Patrimônio e História Local. (Comentários e considerações sobre a reforma educacional do ensino em Portugal final dos anos 1990). Lisboa: Texto Editora, 1904. (p.23-2$).

MAR'TINS, Paulo Henrique N., o Nordeste e a Questão Regional: os equívocos do debate. In República em Migalhas: História Regional e Local. São Paulo: Editora Marco Zero, 1990. $\left(\mathrm{p} \cdot 65-1^{\circ} \$\right)$

PENTEADO, Heloísa Dupas. Metodologia do ensino de bistória e geografia. São Paulo: Editora Cortez, 1994.

PESAVENTO, Sandra Jatahy. História Regional e Transformação Social (Comentário do texto "Região e História"). In Repụ́hlica em Migalhas: História Regional e Local. São Paulo: Editora Marco Zero, $1990,($ ( $\left.) .77-5^{\circ} \xi\right)$.

PIORI, Ângelo, História Regional e Local: Métodos e fontes. In Pós-História. Assis: Editora UNESP, v. 4, 1494. 
SANTOS, 1997, p.196 apud SILVA, Jorge Antonio de Queiroz e. Globalização e História Local. In Revista História \& Ensino. Revista do Laboratório de Ensino de História. Londrina: Editora UEL, 2001. (p. 88).

SEVCENKO, Nicolau. Literatura como missão. Sp. Brasiliense, 1999.

SILVA, Jorge Antonio de Queiroz e. Globalização e História Local. In Revista História \& Ensino. Revista do Laboratório de Ensino de História. Londrina: Editora UEL, 2001

SILVA, T.T. (org.) Identidade e Diferença: A perspectiva dos Estudos Culturais. Petrópolis: Editora Vozes, 2000. pp. 76. (p. 76).

SILVA, Vera Alice Cardoso. Regionalismo: 0 Enfoque Metodológico e a Concepção Histórica. In República em Migalhas: História Regional e Local. São Paulo: Editora Marco Zero, 1990. (p. $\left.45-4^{\circ} \$\right)$.

SILVEIRA, Rosa Maria Godoy. Região e História: Questão de Método. In República em Migalhas: História Regional e Local. São Paulo: Editora Marco Zero, 1990. (p.38-1§).

SOBRAL, José Manuel, Memória Social e Identidade. Experiências Individuais. Experiências Coletivas. In CARDIM. Pedro (org) A História: Entre Memória e Invenção. Portugal: Editora Publicações Europa-América, 1998. (, p.39-1$).

\section{Notes on history teaching of Paraná}

\section{ABSTRACT}

This article propose a reflexion on the Regional History Teaching concerning form and content of History of Paraná, taught by teachers, in the second segment of Primary School and High School, as part of the Enrichment Curricular Project.

Key words: region, identities, memoriam, regionalism, regional history teaching. 